\title{
Schizophrenia and Social Cognition: From Conceptual Bases to Therapeutic Approaches
}

\author{
Luciana de Carvalho Monteiro, Paula Andreia Martins, \\ Marisa Crivelaro and Mario Rodrigues Louzã \\ Institute of Psychiatry, Clinicas Hospital, \\ University of São Paulo School of Medicine \\ Brazil
}

\section{Introduction}

Social cognition has developed independently from neurosciences, with a focus on understanding socioemotional phenomena, i.e., the relationship between the analysis of the social context, of cognitive processing and its base in the central nervous system. It evolved from studies with animals, including experiments such as competing for food, protection strategies and adaptative responses to the social environment of certain species, and application of the resulting knowledge to a better understanding of the evolution of social cognition in human beings. Such studies showed that the development of complex behavior was associated with the increase in the level of response imposed by the environment. This resulted in the ability to deal with unexpected situations and build representations of the relationship with oneself and with others, in order to govern social behavior. Thus, behaviors such as cooperation and selflessness became a key factor in group interaction (Adolphs, 2001, Emery \& Clayton, 2009).

Flaws in social human functioning, including communication with others, preservation of employment, interactions in community and ability to live independently, can be observed in serious metal disorders, such as schizophrenia. Understanding the mechanisms involved in such flaws, differentiating them from basic cognitive deficits, is of the utmost importance both for establishing investigation strategies into dysfunctions in social cognition, and for the development of therapeutic intervention programs.

\subsection{Concept of social cognition}

Social cognition is the capacity to identify, manipulate and adapt behavior in accordance with socially relevant cues detected and processed in a certain context of the environment. To that end, it requires an underlying neural system that manages everything from the stimulus input (perception) to the final result of the process, i.e., manifestation of the adaptive social behavior.

Social cognition guides both automatic and intentional behavior, together with a wide range of other basic cognitive processes, modulating the behavioral response. However, although 
it is generally established that the basic cognitive processes, such as attention, memory and executive functions are necessary for social cognition, they are considered different constructs, as they utilize semi-independent processing systems (Penn et al, 1997; Adophs, 2001; Couture et al, 2006).

Neurocognition and social cognition differ in that the latter is a mediator between neurocognition and social functioning. The distinction between social cognition and neurocognition is the focus of studies not only of social psychologists, but also of researchers in evolution biology and primate behavior. These emphasize the fact that the mechanisms involved in processing information in the human mind are not designed to perform tasks arbitrarily, but rather, to solve specific biological issues imposed by the physical, ecological and social environment encountered by our ancestors in the course of the evolution of the species (Cosmides, 1989 as cited in Penn, 1997)

It may be concluded that neurocognition and social cognition are different manners to comprehend human behavior. Social cognition consists of a mental operation, which is at the core of social functioning, involving the capacity to perceive the intention and disposition of others in a certain context. This includes abilities in emotional and social perception, attribution of causality and empathy, and reflects the influence of the social context (Penn et al., 1997; Couture et al.; 2006).

\subsection{Components of social cognition}

Social cognition can be understood through a conceptual model which involves four specific domains: theory of mind (ToM), attribution style (AS), emotion recognition (ER) and social perception (SP), as indicated in Table 1.

\begin{tabular}{|l|l|}
\hline $\begin{array}{l}\text { Theory of Mind } \\
\text { (ToM) }\end{array}$ & $\begin{array}{l}\text { Ability to understand that others display states of mind that differ } \\
\text { from mine and to make inferences based on the content of such } \\
\text { mental states. }\end{array}$ \\
\hline $\begin{array}{l}\text { Attribution Style } \\
\text { (AS) }\end{array}$ & Particular tendency to explain the causes of events in own life \\
\hline $\begin{array}{l}\text { Emotion Recognition } \\
\text { (ER) }\end{array}$ & $\begin{array}{l}\text { Ability to infer emotional information from emotional expressions, } \\
\text { voice pitch and/or prosody. }\end{array}$ \\
\hline $\begin{array}{l}\text { Social Perception } \\
\text { (SP) }\end{array}$ & $\begin{array}{l}\text { Ability to extract manifest behavioral cues within a certain social } \\
\text { context. It includes the ability to understand social rules and } \\
\text { conventions. }\end{array}$ \\
\hline
\end{tabular}

Table 1. Components of Social Cognition.

\subsubsection{Theory of Mind}

The term "Theory of Mind" (ToM) was initially coined by primatologists Premack and Woodruff in a seminal paper published in 1978 which suggested that chimpanzees were able to infer the mental state of other individuals of the same species (Brüne \& Brüne-Cohrs, 2006). Over time, the term was adopted by developmental psychology to describe the ontogenic evolution of the mental process in infancy and adolescence. 
In psychopathology, the concept of dysfunction of the ToM has been increasingly used in studies involving autistic children. It has been observed that both autistic children and adults (including Asperger's Syndrome), present significant difficulties to apprehend the mental state of other individuals.

Currently, the study of the ToM in other mental disorders has caught the attention of researchers in areas such as schizophrenia and its relation with other aspects of cognition and symptoms, as well as its effect on social behavior (Brüne \& Brüne-Cohrs, 2006; Brüne, 2005). This concept has been a focal point for cognitive psychology, which has dedicated itself to developing several models to explain the ToM. Among them, the Baron-Cohen model (1996) conceives the existence of four cerebral modules which interact to produce the "mind reading" system of human beings (Table 2).

\begin{tabular}{|ll|l|}
\hline $\begin{array}{l}\text { 1. } \\
\text { Intentionality } \\
\text { module }\end{array}$ & $\begin{array}{l}\text { Capacity to interpret a stimulus as intentional based on a desire and } \\
\text { goal formulation. }\end{array}$ \\
\hline $\begin{array}{l}\text { 2. } \\
\text { module direction }\end{array}$ & $\begin{array}{l}\text { Ability to perceive another individual's gaze, and interpret whether } \\
\text { this "gaze" is perceiving the same as the individual's own gaze. }\end{array}$ \\
\hline $\begin{array}{l}\text { 3. } \\
\text { module }\end{array}$ & $\begin{array}{l}\text { Ability to establish relations with own self, with other individuals and } \\
\text { with the perceived objects, i.e. "do you and I perceive the same?". }\end{array}$ \\
\hline module & Theory of Mind & $\begin{array}{l}\text { Ability to integrate the three modules above - perception, desire, } \\
\text { intention - and the construction of coherent theoretical beliefs, } \\
\text { which enable comprehension of the behavior of another individual } \\
\text { and, thus, define and direct the individual's own behavior. }\end{array}$ \\
\hline
\end{tabular}

(Monteiro et al., 2010)

Table 2. Cerebral modules responsible for the ToM, proposed by Baron-Cohen (1996).

Developmental psychology devoted itself to comprehending the origin of this ability in children and how it organizes itself in the several stages of human development.

The ontogenesis of the ToM does not differ significantly from the maturity of other cerebral functions, also following a sequence of acquisitions (eg.: to sit, to stand and to walk) (Brüne \& Brüne-Cohrs, 2006). Thus, at around twelve months old, the child is already able to perceive his/herself, to perceive the agent (eg. his/her mother) and to perceive the object (shared attention), which, according to the Baron-Cohen's conceptual model, includes a fundamental element for the existence of the ToM. After this period, the child progressively develops more complex abilities, such as distinguishing between the representation of a real event and of a hypothetical situation, the perception of his/her own reflex in the mirror and discrimination of false beliefs.

The concept of ToM includes a most fundamental dimension of human awareness for social behavior. It is via this cognitive resource that humans can achieve more sophistication in the relations and communication among individuals of their own group, as well as individuals from other groups, enabling recognition and interpretation of expressions such as irony, concealment, suffering, interest and deceit. Based on such information, the individual is able to anticipate the ideas the other is forming of him/herself, predict events and make critical decisions in the social environment (Monteiro et al., 2010). 


\subsubsection{Attribution style}

Attribution Style is the explanation found by an individual for the positive and/or negative consequences of events in his/her own life.

Most people attribute positive outcomes to themselves (internal attribution) and negative outcomes such as guilt, flaws or other threats, to external factors (external attribution). The subject processes a stimulus, attributes a style to it and reaches a certain causality conclusion.

A study model of Attribution Style stemming from research in social psychology and experimental clinic was the attribution style in depression, which is related to prolonged exposure to uncontrollable aversive events, which result in motivational, cognitive and behavioral deficits (Schill \& Marcus, 1998). In this form of attribution style, individuals believe that there is no way positive outcomes can be achieved or aversive consequences prevented (Seligman, 1990).

The classic pessimistic attribution style can be observed in individuals who tend to explain negative outcomes or failures as internal attribution processes, i.e., blaming themselves, as opposed to external attribution styles in which failure is attributed to the environment. As a rule, the interpretation of these internal causes tends to be stable (continuous) and generalized. Conversely, an individual with an optimistic attribution style interprets negative outcomes, i.e., failure, to external, unstable and specific factors (Peterson \& Seligman, 1984). The style that can be observed in depression seems not to be statedependent, as it tends to remain even upon remission of symptoms. This tendency can be deemed as a trace of susceptibility to depression (Just et al., 2001).

Based on studies involving depressed patients, one can assume that an attribution style can help understand the behaviors and consequences which affect the performance and actions of individuals within the social context.

\subsubsection{Emotion recognition}

Emotion recognition is the ability to infer information from emotional expressions identified in the human face, voice inflection and/or prosody, which is the emotional pitch of human speech.

While there are differences in social rules and customs dictated by culture, facial expressions are universally recognized. Happiness, sadness, anger, fear, repulse, surprise and possibly contemplation are universally detectable emotions. However, unlike universal emotions, social emotions such as guilt, shame and arrogance are specific for each culture (Kohler et. al., 2004a, b).

Emotion plays an important role in preparing action; for that, it is necessary to organize coherent behavioral strategies which rely on efficient collection of information from the environment.

Perception of faces and emotional expressions involve distinct cerebral structures and neurobiological circuits, and are therefore perceived as two separate processes which interact with each other, and are characterized as physiological and cognitive. 
The physiological process seems to be associated with the amygdala, due to its influence in the emotional content of complex perception stimuli, although it is not the only structure involved. The basal nucleus, the one with the largest interconnection with the ventromedial prefrontal cortex, acts in pairing social cues with the appropriate social context, preparing the body for the appropriate behavior and actions (Emery \& Amaral 2000).

The cognitive process consists of conscious experience, pairing stimulus and the corresponding corporal response. This system is regulated by superior brain areas, the cortex of the cyngulus and the frontal lobes.

One of the manners by which an individual can produce, recognize and interpret emotional expressions in the face is by reproducing such expressions in his own body and detecting the feeling it triggers (Adolphs, 1999). This ability is an important component in interpersonal communication, the expressions being used to convey an emotional state, so that the apt "reading of emotions" can supply impressions to lead the individual to act within an appropriate social context (Fuentes et al., 2010).

\subsubsection{Social perception}

Social perception is the ability to pick up cues from behaviors within a given social context and includes the ability to understand social rules and conventions. It consists of forming impressions of others, through the perception of cultural codes and rules that regulate the appropriate actions and behaviors within a given social context. The ability to identify the typical behaviors of each context and culture reduces the occurrence of gridlocks in the relationship among individuals in a given group (Del Prette \& Del Prette, 2009, Rocca et al., 2010).

Social perception enables the appropriate interpretation of the social world and the control over it. It plays an important role in decision-making and in situations requiring interaction with other individuals. It is with basis on this "social reading" that the formation of mental schemes is structured.

\subsection{Neuroanatomical substrates and information processing}

The neural substrates involved in the processing of social stimuli include the cortical regions of the temporal lobe, while the amygdala, the right somatosensory cortex, the orbitofrontal cortex and the cyngulate are involved in connecting the perception of the social stimulus to motivation, emotion and cognition (Adolphs, 2001; Ochsner, 2004).

The medial prefrontal cortex is a crucial component in mediating neural systems of perception of the social context, promoting adaptation of behavior (Krueger and cols. 2009).

Social reasoning and decision-making are associated with the ventromedial prefrontal cortex, while emotional awareness of facial expression involves the amygdala. The ability to simulate and empathize is associated with the right somatosensorial cortex, while automatic response is related to the insula (Bechara, Damasio \& Damasio, 2003).

Social Cognition, together with a wide range of other basic cognitive processes, such as attention, memory, language and the executive functions, govern automatic and intentional behavior, regulating the behavioral response (Penn et al., 1997; Couture et. al., 2006). 
Social information processing is proposed by Sapute and Lieberman (2006), from a neural base model divided into reflexive systems and reflective systems (Table 3). The reflexive system operates through automatic processes, whereas the reflective system operates through controlled processes.

\begin{tabular}{|l|l|}
\hline Reflexive System (automatic processes) & Reflective System (controlled processes) \\
\hline Parallel Processing & Serial Processing \\
\hline Fast Operations & Slow Operations \\
\hline Slow Learning & Fast Learning \\
\hline Non Reflective Awareness & Reflective Awareness \\
\hline More ancient Filogenetic Structure & Newer Filogenetic Structure \\
\hline Representation of symetrical relations & Representation of asymetrical relations \\
\hline Representation of ordinary cases & Representation of special cases and abstract concepts \\
\hline
\end{tabular}

Table 3. Characteristics of the Reflexive and Reflective Systems (Monteiro and Louzã 2010).

The automatic processes involve the amygdala, the basal ganglia, the ventromedial prefrontal cortex, the dorsal anterior cingulate cortex and the temporal lateral cortex, being these regions involved in encoding traits and evaluating the implications of an observed behavior (Monteiro e Louzã, 2010).

The prefrontal lateral, the posterial parietal, the prefrontal medial cortices, the anterior rostral cingulate and the areas of the medial temporal lobe, including the hippocampus, are involved in voluntary processes, referred to as the reflexive system. These regions are responsible for exploring the inferred objects in the mind, and also for apprehending the situational information added to previous knowledge, in order to alter the interference of observed behaviors.

Automatic processing does not require much effort, for which reason it is considered qualitatively different from controlled processing. In automatic processing, the evaluation is out of the realm of conscience, does not receive attention modulation and is hard to regulate and control. The processing occurs in a parallel manner, involving tasks already known and performed, and thus considered stereotyped and automatic.

Controlled processing is intentional, voluntary or requires effort. It occurs in consciousness and is deemed slow; regulation is accessible and requires attention resources. The processing is done in series, so that information is processed in a step by step manner, enabling the individual to deal with new and difficult tasks, never before performed. Processing appears later in development terms, and involves declaratory language, reasoning and the ability to reflect and ponder. It utilizes complex levels of cognitive processing, such as: semantics, synthesis and abstraction.

\subsection{Evaluation paradigm}

The conceptual model of social cognition has been used to investigate both social competence functioning, through standardized instruments, and the structures involved in this functioning, through neuroimaging studies. 
The most cited instruments in the current literature according to each cognitive domain are listed in Table 4.

\begin{tabular}{|l|l|}
\hline Social Cognition Domains & Tests \\
\hline Emotion Recognition & $\begin{array}{l}\text { Bell-Lysaker Emotion Recognition Test, Facial Affect } \\
\text { recognition, Facial Emotion Identification Test, Facial } \\
\text { Expression of Emotion, Penn Emotion Acuity Test, Pictures } \\
\text { of Facial Affect, Videotape Affect Perception Test, } \\
\text { Emotional Differentiation Task, Facial Emotion } \\
\text { Discrimination Test, Voice Emotion Discrimination Test, } \\
\text { Mayer-Salovey-Caruso Emotional Intelligence Test, Prosody } \\
\text { Task, Vocal Affect Recognition and Voice Emotion } \\
\text { Identification }\end{array}$ \\
\hline Social Perception & $\begin{array}{l}\text { Half-Profile of Nonverbal Sensitivity (PONS), Social } \\
\text { Behavior Sequencing Task (SBST), Social Perception Scale } \\
\text { (SPS), Picture Arrangement Subtest (WAIS), Situational }\end{array}$ \\
& $\begin{array}{l}\text { Feature Recognition Test, Schema Component Sequencing } \\
\text { Task, Social Cue Recognition Task, Social Cue Recognition } \\
\text { Task-revised, Social Stimuli Sequencing Task and } \\
\text { Comprehension Subtest (WAIS) }\end{array}$ \\
\hline Theory of Mind (ToM) & $\begin{array}{l}\text { Attribution of Intention errors, Advanced ToM Scale, } \\
\text { Hinting Task, The Awareness of Social Inference Test } \\
\text { (TASIT), ToM stories, Tom Picture Stories, Tom Vignettes, } \\
\text { Faux Pas Task, Eyes Test and Implicit Mentalizing Task }\end{array}$ \\
\hline Attributional Style & Ambiguous Intentions Hostility Questionnaire (AIHQ) \\
\hline Social Functioning & $\begin{array}{l}\text { Nurses' Observation Scale for Inpatient Evaluation (NOSIE), } \\
\text { Personal and Social Performance Scale (PSP), Social } \\
\text { Adjustment Scale (SAS), Social Behavioral Scale (SBS), } \\
\text { World Health Organization Disability Assessment Schedule } \\
\text { (WHODAS) }\end{array}$ \\
\hline
\end{tabular}

(M. M. Kurtz \& C. L. Richardson, 2011; A-K.J. Fett et al., 2011)

Table 4. Selected Tests for the Social Cognition Assessment.

\section{Social cognition and schizophrenia}

Over recent years there has been a growing interest in the study of Social Cognition impairments in schizophrenia. These studies have explored the social cognition of individuals at ultra-high risk to develop psychosis (especially schizophrenia), the first psychotic episode and chronic schizophrenia. Besides, some studies have also measured social cognition impairments in persons with high risk to schizophrenia (relatives of patients, especially first degree relatives, including parents and children of schizophrenic patients) and individuals with schizotypy. 
The term ultra-high risk (UHR) has been used to define individuals that fulfill operational criteria for "psychosis risk syndrome", measured with the use of structured interviews such as the The Structured Interview for Prodromal Symptoms and the Scale of Prodromal Symptoms - SIPS/SOPS (Miller, 2003) or the Comprehensive Assessment of At Risk Mental State - CAARMS (Addington, 2004). Sometimes, the expression "prodromal state" or "prodrome" or "prodromal phase" is also used to refer to UHR individuals.

Current findings have demonstrated that individuals at prodromal state, ultra high risk and first psychotic episode may already present impairments, which can still be found in the remission period and/or symptoms relapse.

\subsection{Studies in prodromal, first-episode and chronic schizophrenia}

\subsubsection{Attribution style}

Psychotic patients have a tendency to attribute negative events to an external agent, and this externalization trend is associated with delusions. The tendency to externalize is particularly evident in persecutory and self-reference delusions, in which individuals interpret the intentions of others as personal and negative (Janssen et. al., 2006). Aakre (2009) studied the attribution style of currently paranoid patients, comparing them to paranoid patients in remission, non-paranoid patients in remission and healthy controls, and observed that currently paranoid patients demonstrated a greater tendency to "external-personal attributions" to negative events. The other groups of patients also presented a greater tendency to adopt internal-personal and internal-universal attributions to negative events. Mizhara (2008) evaluated patients with schizophrenia, with schizoaffective disorder and with schizophreniform disorder, and verified a direct relation between the intensity of the psychopathology and an internalizing attribution style.

Krstev (1999) studied 62 first-episode patients and observed a lower rate of suspiciousness (measured through BPRS) and more depression (Beck Depression Inventory) predicted higher scores of internal attributions for negative events. An et al. (2010) observed an association between persecutory symptoms and perceived hostility bias in first-episode patients.

The attribution style bias associated with paranoid symptoms may not only be present in first-episode patients, but also before the beginning of frank psychotic events, and evolves upon diagnozing the individual. Patients with schizophrenia perceive hostility more acutely, associated with positive symptoms; UHR individuals present less bias to perceive hostility and react aggressively to ambiguous situations. This low tendency to aggressiveness, however, could be a distinct trait of UHR patients. These also presented a tendency to avoid hostile situations refraining from approaching another person, and have a tendency to blame such person. (An et. al., 2010). However, Janssen (2006) did not observe alterations of attribution style in first-degree relatives of non-affective psychosis patients and in individuals with sub-clinical psychotic experiences.

\subsubsection{Theory of Mind (ToM)}

Studies have demonstrated that schizophrenic patients present significant impairments in the ability to infer the mental state of other individuals. These deficits are more significant in 
the acute phase of the disease, and seem to persist during remission periods. The alterations observed may indicate a possible marker of schizophrenia (Sprong, 2009; Bora, 2009).

Chung et.al. (2007) suggest that mild deficits in social cognition in the prodomic phase of schizophrenia are verified, and could be attributed to a prefrontal dysfunction. Some studies have demonstrated cognitive impairment in ToM tasks in ultra high risk individuals, and these deficits could be risk markers evolving over time, to differentiate functional and clinical deterioration (Bonshtein, 2006).

There is a significant association between ultra high risk and impairments in ToM tasks, verified through errors committed by such individuals in false belief tasks of first and second degree, although these individuals present equivalent performance in superior order tasks, which are not significantly different from the performance of individuals with schizophrenia and the good performance of healthy adult controls. Evidence of impairment of brain circuits associated with mentalization were evaluated by means of functional magnetic resonance, comparing the intensity of activation of different areas of the brain during the performance of ToM tasks by the families of schizophrenic individuals, with and without a history of psychotic symptoms, and controls. The first ultra high risk group activated several areas of the prefrontal cortex less intensely when compared to the second group, which could suggest, albeit inconclusively, that ToM deficits are trace-dependent (Tonetti et. al., 2008).

Koelkebeck, (2010), investigated ToM in first-episode schizophrenia patients and healthy controls, and analyzed the relationship with neuropsychological and psychopathological functioning. Alhtough first-episode patients did not present differences when compared with the control group in response to videos with random movement, moderate cognitive deficits were observed in inaccurate description used and less ToM-related vocabulary when responding to socially complex ToM video sequences. Deficits in ToM are present from the initial stage of the disease, and the impairments verified may be independent from the clinical history, from alexithymia and from empathy.

Bertrand (2007) assessed ToM in first-episode of schizophrenia spectrum psychosis and healthy controls. Differences were observed between the groups in the Hinting Task and the Four Factor Test of Social Intelligence, but the Four Factor Test of Social Intelligence demonstrated the strongest effect in the group, and the effects observed remain significant. The findings did not present correlation with the intensity of symptoms.

Review and meta-analysis show that ToM deficits are more intense in the acute phase of the disease, although it persists even during periods of remission. Healthy relatives of individuals with schizophrenia and individuals with high scores of schizotypy also present deficits of ToM. Intellectual deficits seem to influence the impairment of ToM in patients in remission (Bora 2009, Bora et al. 2009).

Achim et al. (2010) evaluated the relationship between levels of empathy, performance in mentalization and clinical symptoms of first psychotic episode, and healthy individuals. These results were also compared with previous studies in patients with chronic schizophrenia through meta-analysis. The authors observed that the evaluations of the interpersonal reaction index (IRI) did not differ significantly between first-episode patients and the control group. In first-episode patients, there was no correlation between IRI and 
positive and negative symptoms, or symptoms of general psychopathology, but a significant negative correlation between the Liebowitz Social Anxiety Scale and Perspective taking was observed. A positive correlation between the Empathic concern subscale and our ToM task was also observed. Patients in first-episode of psychosis presented lower impairment of empathy than chronic schizophrenic patients.

The literature review carried out by Tonelli et al (2009) identified fifteen studies which evaluated schizotypal traces and the relations between vulnerability to psychosis and alterations in ToM processing. Most studies suggest that individuals with high scores in schizotypy scales, relatives of schizophrenic patients, who present deficits in ToM processing, could suggest a dependent character trait. Some studies have confirmed the hypothesis that schizophrenic individuals with a predominance of negative symptoms and disorganization, score lower in ToM tasks than individuals with a predominance of positive symptoms. ToM alterations in schizophrenic patients could derive from primary general cognitive deficits, since the brain structures involved in processing Social Cognition and ToM are also called upon for processing other non social cognitive functions (Tonelli et al. 2009).

\subsubsection{Emotion recognition}

Difficulties in emotion recognition are present before the manifestation of psychosis in high risk individuals (Thompson et al 2011). Edwards (2001) evaluated facial and prosody emotion recognition in individuals with first episode psychosis and controls. It was observed that the participants did not differ in the understanding of the words used to describe emotions. However, slight but consistent deficits in the recognition of fear and sadness in both channels of communication were observed. These findings can suggest a characteristic deficit, consistent with dysfunction of the amygdala in schizophrenia and related psychosis (Amminger 2011). These data suggest that deficits in facial emotion recognition may serve as an endophenotype for schizophrenia (Addington et. al., 2008, Li et. al., 2010).

The study of Kohler et al. (2009) revealed that schizophrenic patients present deficits in emotion recognition, irrespective of the type of task and factors that may act as moderators of the impairment observed, such as the clinical symptoms and anti-psychotic treatment. Patients with schizophrenia present flaws in the recognition of fear and in the interpretation of social cues in faces. Recent studies have demonstrated limbic hyperactivity in these patients when they see nonfearful and fearful faces, as compared with basal values. Hyperactivity of the amygdala can also be detected when individuals with schizophrenia cannot adequately recognize fearful faces (Morris et al., 2009).

Eack et al. (2010) suggest that deficits in emotion recognition in schizophrenic and ultra high risk individuals could be related to difficulties in visual perception, which is also observed in individuals with schizophrenia. In this respect, alterations in neurocognition can interfere with the ability to discriminate emotions, consequently impairing social cognition. Sachs et al. (2004) compared patients with schizophrenia and healthy volunteers in computerized tasks of recognition of emotion. They were also tested with a standard neuropsychological battery and rated for positive and negative symptoms. Patients with schizophrenia performed more poorly than controls in all the tasks of emotion recognition. The most 
significant difficulties were verified in discriminating happiness, differentiating sad from happy faces, and facial memory. The latter may be correlated with the severity of the negative symptoms. These findings suggest that the notion of difficulty in emotion recognition in schizophrenia may be associated with specific cognitive deficits.

Addington (2006) evaluated patients with first episode psychosis, schizophrenia patients with multiple episodes of psychosis and controls. The individuals were evaluated in two tasks of facial recognition, a complete cognitive battery and a measure of social functioning. Both patients were clearly impaired when compared with the controls in social cognition and recognition of facial emotions. Significant associations between the functioning of facial recognition and recognition of facial emotions were observed in all three groups. However, there was no evidence that the recognition of facial emotions partially affects the mediation between the relations of social and cognitive functioning.

Two recent reviews highlight some points in the deficit of emotion recognition in schizophrenia. There is controversy as regards the kind of emotion whose deficit is more aggravated, while in others, any kind of emotion is poorly identified. The association with clinical symptoms is likewise unclear, and both positive and negative symptoms could influence emotion recognition. The fact that the deficit of emotion recognition is pervasive in the disease from the beginning and remains along its course suggests that it is a trait-marker of schizophrenia (Morris et al. 2009, Marwick e Hall 2008).

\subsubsection{Social perception}

There are few studies in this area, although researchers have shown interest in exploring the perception of social interactions in individuals with psychoses. Studies have demonstrated impairments in schizophrenia, usually expressed in a more subtle manner in first-episode and ultra high risk individuals. Couture (2008) evaluated UHR individuals, schizophrenic patients and controls, proposing a task in which the participants made social judgments of unknown faces. The findings demonstrated that the ultra high risk group classifies unreliable faces as more reliable. However, they did not present differences when compared to the control group when judging reliable faces. Ultra high risk individuals classified dishonest faces as positive, more frequently that the controls. Ultra high risk individuals presented partial response to unreliable faces, when compared with schizophrenic individuals and controls (Thompson et. al., 2011).

Green (2011) evaluated the relationship between the domains of social cognition: social perception and emotion recognition and neurocognition in high risk, first-episode, and schizophrenic individuals and controls. The authors observed impairment in cognitive performance and in all the areas of social cognition in all the groups of the sample. Performance differences between the groups were comparable between the phases of the disease, not evidencing progress or improvement. Pinkham (2007) evaluated social perception and emotion recognition in ultra high risk individuals, individuals in the early stages of the schizophrenia spectrum, chronic schizophrenic patients and healthy controls. Ultra high risk individuals did not differ significantly from the control group. However, individuals in the early stages of the disease and chronic schizophrenics presented significant deficits, demonstrating poorer performance than controls, but not differing from each other, although there is evidence that deficits in social skills can be observed from the 
onset of the disease. The findings suggest that deficits in social perception skills can be a vulnerability marker for schizophrenia.

Although the results point out deficits in ultra high risk and schizophrenic individuals, one must understand the variations in the course of the disease, as well as observe factors such as: stress, previous experiences with the disorder and current experiences, which may be dependent on or independent from the progress of the disorder. Longitudinal studies in this area are required to better explain the course and severity of these difficulties (Couture et al., 2008).

\subsection{The impact of social cognition impairments on functioning}

Social cognition is a specialized area of cognition, which enables the individual to adapt to group or social life. Impairments in social cognition result in difficulties in the social functioning of individuals with schizophrenia.

Alterations in social cognition result in flaws in these individuals' social functioning, obstructing their independent living, impacting decision-making and situations in which the interaction with other individuals is required. These flaws result in day to day difficulties, such as preservation of employment and community life, due to the inability to interpret and have control over the social world around them. It is based on this "social reading" that the mental schemes are structured. For these individuals, there is impairment in relationships, in interpreting a given stimulus, in perceiving another individual's gaze, in the formation of relationships with themselves and with others, in integrating perception, desire, beliefs and intentions.

The individual who presents defective processing of ToM is prevented from subjectively representing an important variable of reality, the mental state of others, impairing the distinction between subjectivity and objectivity. Deprived of the ability to accurately interpret the mental content of others, attributes to them feelings and thoughts that may be offensive, threatening or seductive, thus representing a possible mechanism that favors the appearance of paranoid and erotomaniac delusions.

Deficits in attribution style lead these individuals to perceiving hostility more intensely. Ambiguous situations in which the contextual cues are scarce may lead an individual to interpret the environment or people as socially threatening, provoking avoidance behaviors and ensuing isolation, since he/she believes that others do not have good intentions, an additional fuel for paranoid ideation (Bentall et al., 2001).

The ability for social play is dependent upon the systematization and hierarchization of a series of cues supplied in each social context. This is subject to how the individual has access to the mental universe of others with all the network of contextualization it requires. Emotion plays an important role in preparation for action, which requires organizing coherent behavioral strategies, and which, in turn, depend on the efficient perception of environmental cues.

Different cultures exist and diverge in terms of social rules and customs. But when it comes to facial expressions, emotion is universally recognized. A deficit in this kind of cognition, prevents the individual from inferring emotional information from perceived emotional 
expressions, voice pitch and/or prosody, consequently preventing him/her from reproducing the facial expression in his/her own body, and detecting the feeling it triggers. This results in difficulties to identify the directions to be followed within an adequate social context (Fuentes, et. al., 2010).

Deficient functioning of social perception impairs the perception of social cues expressed in the behavior within a given social environment. Thus, the individual is unable to understand social rules and conventions which govern behavior within specific social contexts.

\section{Therapeutic approaches}

Therapeutic interventions that improve deficits in social cognition are of the utmost importance, considering the impact that these flaws have in functioning, quality of life and socio-economic cost of the disease, be it in its initial stages or in the chronic state.

\subsection{Intervention models}

Three treatment strategies have been used: a) psychotherapeutic rehabilitation aimed at reducing the psychotic symptoms and functional improvement; ) specific medication targeted at the cognitive mechanisms related to the psychotherapeutic rehabilitation; and c) use of anti-psychotic medication to reduce symptoms and facilitate the patient's engagement in the cognitive rehabilitation (Swerdlow, 2011).

\subsection{Pharmacological interventions}

There is some evidence in different meta-analyses, that antipsychotic drugs improve neurocognition in schizophrenic patients. First generation antipsychotics improved neurocognition with a mean effect size of 0.22 , with a range between $0.13-0.29$ for the majority of cognitive functions (Mishara and Goldberg, 2004). Other authors concluded that second generation antipsychotics are superior to first generation antipsychotics, improving overall cognitive function with an effect size of 0.24 . They also concluded that different antipsychotics might have differential effects on the different cognitive domains (Woodward et al. 2005). Thornton et al. (2006) examined the influence of different antipsychotics on long-term memory of schizophrenic, schizoaffective and schizophreniform patients and showed that antipsychotics with less anticholinergic effect produce a more robust improvement of the long-term memory. Other agents (e.g., cholinergic, glutamatergic, dopaminergic) showed conflicting results so that there is no clear evidence that these drugs improve cognition in schizophrenia (Barch 2010).

There are relatively few studies that addressed the influence of antipsychotics alone in social cognition. Sergi et al. (2007) evaluated social cognition during a double blind study comparing olanzapine, risperidone and haloperidol. They administered several social cognition measures (including tasks of emotion perception and social perception) at baseline, after 4 and 8 weeks of treatment. They developed a summary score of social cognition and observed no effect of antipsychotic treatment either within-group or betweengroups on social cognition. 
In relation to ToM, Savina and Beninger (2007) cross-sectionally compared groups of schizophrenic patients taking different antipsychotic drugs with healthy controls and concluded that patients treated with clozapine and with olanzapine had a better performance than patients taking risperidone or first generation antipsychotics. The clozapine and the olanzapine groups performed similarly as the controls. Mizrahi et al. (2007) evaluated the ToM of 17 drug-free psychotic patients (schizophrenia, schizophreniform and schizoaffective disorder) at baseline and every 2 weeks for 6 weeks, after initiating antipsychotic treatment (different second generation drugs) and observed an improvement in ToM performance. However, the authors could not exclude the influence of a practice effect due to the repetition of the ToM task and call attention to the lack of a placebo-control group. Recently, Pedersen et al. (2011), a randomized double-blind placebo controlled trial showed an improvement in ToM in patients treated with intranasal oxytocin for two weeks.

The influence of antipsychotic drugs in emotion recognition has been studied by several authors with positive (Cabral-Calderin et al. 2010, Fakra et al. 2009, Behere et al. 2009, Ibarrarán-Pernas et al. 2003) and negative results (Lewis and Garver 1995). The largest study of the impact of antipsychotic drugs on emotion recognition was conducted together with the CATIE study. This five-arm double-blind randomized study compared the effectiveness of olanzapine, risperidone, ziprasidone, quetiapine and perphenazine in chronic schizophrenic patients. Patients $(n=873)$ were tested before randomization and two months after treatment. All antipsychotics showed a small, nonsignificant, improvement in emotion recognition; a lower baseline emotion recognition scores and higher baseline neurocognitive functioning predicted a better improvement in emotion recognition after two months of treatment (Penn et al. 2009). In a single dose, placebo controlled crossover trial, modafinil $(200 \mathrm{mg})$ improved the recognition of sad faces in first episode psychosis (Scoriels et al 2011).

Littrell et al (2004) showed an improvement in social perception in patients treated with olanzapine. Treatment with oxytocin improved social perception in schizophrenia (Pedersen et al. 2011).

Considered together, these studies show some improvement of social cognition deficits with antipsychotic treatment. Nevertheless, not all studies were specifically designed to study this subject, and there are other methodological issues such as the use of different tests to evaluate social cognition. The issue of the learning effect by repeating the task after a few weeks is also not clearly addressed. It is not clear yet whether the influence of antipsychotics (or other drugs) on social cognition is direct or indirect, due to the improvement of psychopathology (especially positive symptoms).

\subsection{Rehabilitation}

Studies published in the last decades investigated the efficacy of psychosocial rehabilitation in medication-resistant positive symptoms, such as cognitive-behavioral therapy and social skills training. Residual symptom reduction is a major therapeutic goal. However, patients and their families in functional impairments at work, education, autonomy and socialization as a major concern. Difficulties in performing activities that require minimum critique of the real world is common in schizophrenia. Lack of social skills occurs even after a successful 
treatment of symptoms of the disease, presenting early and persisting all through life. (Granholm et al., 2009).

Around 2/3 of patients cannot achieve or sustain basic social roles such as a job, conjugal life, paternity/maternity and integration in the community. Rehabilitation approaches, such as social and vocational skills training and cognitive behavioral therapy aim at helping patients reduce impairments in social role functioning (Seth et al., 2010).

Social skills training aims at improving social impairments that are typical in schizophrenia, with strategies based on the application of principles of social learning. In the studies cited by Kurzban et al. (2010), several strategies have been implemented, such as vocational skills training, social training, self-care skills, communication skills and assertiveness training.

The studies in this area have indicated reduction of symptoms and improvement of functioning with different forms of cognitive therapies (Swerdlow, 2011), which can be computer-based or manual (Park et al., 2010). Generally speaking, cognitive therapies develop compensatory strategies for information learning and retrieval. They act in prefrontal areas of the brain, in charge of working memory and attention (Swerdlow, 2011).

\subsubsection{Neuropsychological rehabilitation and social cognition}

It is unlikely that interventions focused on neurocognition are sufficient to correct deficits in social cognition, since only around $40 \%$ of schizophrenics present specific cognitive deficits (Horan et al., 2009), although they may also present social inability (Horton \& Silverstein, 2008).

Several studies relate social impairments to the high rate of relapse and low quality of life. However, recent attempts at associating cognitive training to social skills training have had partial success. Intense training of neurocognition improves cognitive deficits (attention, memory and executive functions, etc.), but does not automatically extend to social functioning (Choi \& Kwon, 2006).

Non-pharmacological interventions aimed at cognitive deficits in schizophrenia are usually referred to as "cognitive remediation" or "cognitive training" (Galderisi et al., 2009). Cognitive remediation programs are rarely based on a clear theory, and quite often rely more on practice than on learning. Several approaches of cognitive training have been developed, such as computer-based repetitive cognitive exercises, or its pen and paper version, learning strategies for organization of information or adaptative strategies involving the environment and behavior, and strategies for learning, such as: instructions, positive reinforcement, etc. In a meta-analysis study on the efficacy of cognitive remediation therapy, significant cognitive improvement was verified, and a modest improvement in social functioning. Cognitive remediation in itself cannot address all the deficits and must be integrated with broader rehabilitation programs, including occupational therapy, professional counseling, self-care, among other therapeutic activities (Wykes et al., 2011, Patel et al., 2010).

The studies lean towards the development of strategies of cognitive rehabilitation, associating specific cognitive interventions with the domains of social cognition. The 
consensus battery of cognitive tests, MATRICS, identified social cognition as one of the seven critical cognitive domains for understanding schizophrenia (Horton \& Silverstein, 2008). Some studies indicate that cognitive remediation improves cognitive performance, symptoms and psychosocial functioning. Other authors believe that cognitive remediation will be ineffective if it ignores social cognition and its components, and reviews suggest that the cognitive deficits are more associated with functional outcomes than to the psychiatric symptoms (Veltro et al., 2011).

Presently, there are two different types of intervention focused on developing social cognition. The first, called "target intervention", seeks to stimulate only one specific domain of social cognition. The second, named "broadbased interventions", consists of more eclectic and complex programs, which incorporate multiple domains. In three reviews, a significant improvement of the cognitive domain in question was found with both forms of intervention. However, it was not possible to claim a direct influence on social cognition. It was also noted that individuals with schizophrenia benefit from interventions which improve linguistic skills, especially those related to social cognition (Horton \& Silverstein, 2008).

In a recent review of 19 studies and 692 patients, an effect size of 0.71 was found in emotion recognition in faces, small effect $(\mathrm{d}=0.46)$ in theory of the mind, and nonsignificant effect on social perception and attribution style. However, the generalization measures revealed a significant effect size in total symptoms (0.68) and functioning in the community. The effects of training in positive and negative symptoms were not significant (Horton \& Silverstein, 2008). The limitation of training in social cognition in positive and negative symptoms described in this review may reflect the multidetermined nature of these domains of the disease, such as non-adherence to medication and family dysfunction. In turn, the verification of moderate effect size in general symptoms suggests an effective influence of general psychiatric symptom, such as depression and anxiety (Kurtz \& Richardson, 2011).

According to Medalia \& Choi (2009), several factors have influence over a positive treatment response for cognitive remediation training and social skills, such as training of the therapist, motivation of the patient, intensity and type of training and the base cognitive resources, which may be more or less preserved. The negative symptoms, however, may influence commitment to the work, relationship and treatment (Kurzban et al., 2010).

In most studies, the patients with the longest history of the disease were better prepared to make use of the social cognition intervention. The generalization of training in social cognition was also larger in young samples, with even more evident improvement when the treatment had longer duration and included prescribed medication (Kurtz \& Richardson, 2011).

Nowadays, a large number of approaches is available. However, rather than envisage an extended intervention program which will encompass all, health professionals should devise customized treatments, avoiding unrealistic expectations. The disorder is heterogeneous in nature and may go through many changes over time (Penn et al., 2008). 


\begin{tabular}{|c|c|c|c|}
\hline Studies $(\mathrm{n}=10)$ & Sample & Type of Intervention & Major Findings \\
\hline $\begin{array}{l}\text { Choi \& } \\
\text { Kwon, } 2006\end{array}$ & $\begin{array}{l}34 \text { patients } \\
\text { diagnozed with } \\
\text { schizophrenia }\end{array}$ & $\begin{array}{l}\text { Training in psychiatric } \\
\text { rehabilitation standard } \\
\text { plus social cognition } \\
\text { enhancement training } \\
(\text { SCET) }\end{array}$ & $\begin{array}{l}\text { Some social cognition skills improved } \\
\text { rapidly after } 2 \text { months of treatment; } \\
\text { however, other skills only improved } \\
\text { after } 6 \text { months of treatment }\end{array}$ \\
\hline $\begin{array}{l}\text { Penn et al., } \\
2007\end{array}$ & $\begin{array}{l}17 \text { hospitalized } \\
\text { patients diagnozed } \\
\text { with schizophrenia }\end{array}$ & $\begin{array}{l}\text { Social cognition and } \\
\text { interaction training } \\
(\mathrm{SCIT})\end{array}$ & $\begin{array}{l}\text { The patients exhibited better emotion } \\
\text { recognition, theory of mind and reduced } \\
\text { tendency to hostility towards others }\end{array}$ \\
\hline $\begin{array}{l}\text { Horan et al., } \\
2008\end{array}$ & $\begin{array}{l}31 \text { stabilized clinic } \\
\text { patients } \\
\text { diagnozed with } \\
\text { schizophrenia }\end{array}$ & $\begin{array}{l}\text { Program of training in } \\
\text { social cognition }\end{array}$ & $\begin{array}{l}\text { The participants of the social training } \\
\text { group presented significant } \\
\text { improvement in facial emotion } \\
\text { recognition }\end{array}$ \\
\hline $\begin{array}{l}\text { Horton \& } \\
\text { Silverstein, } \\
2008\end{array}$ & $\begin{array}{l}34 \text { deaf and } 31 \text { non } \\
\text { deaf schizophrenic } \\
\text { patients }\end{array}$ & $\begin{array}{l}\text { Training of cognition and } \\
\text { social cognition }\end{array}$ & $\begin{array}{l}\text { Non-deaf subjects did better at social } \\
\text { cognition tasks including linguistic skills } \\
\text { Deaf subjects exhibited better results } \\
\text { in social cognition tasks which } \\
\text { included non-linguistics tasks; facial } \\
\text { affect processing (FAP) and ToM were } \\
\text { effective in non-deaf subjects } \\
\text { FAP consists of a more efficient } \\
\text { mediator in deaf subjects }\end{array}$ \\
\hline $\begin{array}{l}\text { Wykes et al., } \\
2008\end{array}$ & $\begin{array}{l}29 \text { patients } \\
\text { diagnozed with } \\
\text { schizophrenia }\end{array}$ & $\begin{array}{l}\text { Individualized cognitive } \\
\text { rehabilitation }\end{array}$ & $\begin{array}{l}\text { Improvement in memory, mental } \\
\text { flexibility and planning } \\
\text { Secondary improvement of symptoms, } \\
\text { social contact and self-esteem }\end{array}$ \\
\hline $\begin{array}{l}\text { Galderisi et } \\
\text { al., } 2009\end{array}$ & $\begin{array}{l}60 \text { randomized } \\
\text { patients } \\
\text { diagnozed with } \\
\text { schizophrenia }\end{array}$ & $\begin{array}{l}\text { Structured leisure activities } \\
\text { (SLA) and social skills and } \\
\text { neurocognitive } \\
\text { individualized training } \\
\text { (SSANIT) }\end{array}$ & $\begin{array}{l}\text { After } 6 \text { months of treatment, patients } \\
\text { with SSANIT training did better in } \\
\text { social and personal functioning than } \\
\text { those who underwent only SLA. }\end{array}$ \\
\hline $\begin{array}{l}\text { Park et al., } \\
2010\end{array}$ & $\begin{array}{l}91 \text { hospitalized } \\
\text { patients } \\
\text { diagnozed with } \\
\text { schizophrenia }\end{array}$ & $\begin{array}{l}\text { Social skills training with } \\
\text { traditional role playing } \\
\text { (SST-TR) and Social } \\
\text { skillls training through } \\
\text { virtual reality (SST-VR) }\end{array}$ & $\begin{array}{l}\text { The SST-VR group showed more } \\
\text { improvement in conversation skill } \\
\text { assertiveness, when compared with } \\
\text { the SST-TR group, but less in non- } \\
\text { verbal skills. }\end{array}$ \\
\hline $\begin{array}{l}\text { Patel et al., } \\
2010\end{array}$ & $\begin{array}{l}85 \text { randomized } \\
\text { patients with } \\
\text { schizophrenia }\end{array}$ & $\begin{array}{l}\text { Standard Cognitive } \\
\text { Remediation Therapy } \\
\text { (CRT), plus self-care }\end{array}$ & $\begin{array}{l}\text { Improvement of working memory in } \\
\text { CRT }\end{array}$ \\
\hline $\begin{array}{l}\text { Sparks et al., } \\
2010\end{array}$ & $\begin{array}{l}30 \text { patients with } \\
\text { schizophrenia or } \\
\text { schizoaffective } \\
\text { disorder and } 25 \\
\text { healthy controls }\end{array}$ & $\begin{array}{l}\text { Social cognition training } \\
\text { involving emotion } \\
\text { recognition }\end{array}$ & $\begin{array}{l}\text { Participants with schizophrenia kept } \\
\text { the worst performance in identifying } \\
\text { emotional states in tests of } \\
\text { discrimination of emotions in faces, } \\
\text { when compared with the healthy } \\
\text { controls group }\end{array}$ \\
\hline $\begin{array}{l}\text { Veltro et al., } \\
2011\end{array}$ & $\begin{array}{l}24 \text { individuals } \\
\text { diagnozed with } \\
\text { schizophrenia }\end{array}$ & $\begin{array}{l}\text { Cognitive emotional } \\
\text { rehabilitation (REC) vs } \\
\text { Problem solving training } \\
\text { (PST) }\end{array}$ & $\begin{array}{l}\text { Both training methods were efficient } \\
\text { in psychopathological measures and } \\
\text { social functioning }\end{array}$ \\
\hline
\end{tabular}

Table 5. Programs of training in social cognition and neuropschological rehabilitation. 


\section{Conclusions and limitations}

\subsection{Conclusions}

Social cognition is of great importance in human interaction, enabling the adaptation of behavior in a wide range of social contexts. Deficits in social cognition, including all of its domains, are observed along the course of schizophrenia, even in the early stages of the disorder. It results in significant functional impairment, hindering independent living. Deficits in social cognition are also observed in first degree relatives of patients with schizophrenia and in individuals with schizotypal characteristics.

Interventions aimed to improve social cognitive abilities, minimizing the impact of deficits on their socio-emotional functioning are increasingly necessary.

Pharmacological treatments, especially second generation antipsychotics, seem to improve neurocognitive performance. However, the effects of such drugs on social cognition are still unclear and more studies are required to clarify their impact on social cognition.

Cognitive rehabilitation, associated with pharmacological treatment, has shown to be effective in improving social cognition in schizophrenia. However, it is still not possible to determine whether such improvements are preserved after the discontinuation of the intervention. It is likewise unclear whether these improvements are generalized beyond the therapeutic environment.

\subsection{Limitations}

The diagnostic criteria used, both for schizophrenia and for other psychotic disorders, are still controversial. In studies involving ultra high risk populations, additionally to the difficulty to characterize the individuals, the duration of follow up can impair the results of the study, as for some individuals the period to convert to psychosis or any other mental disorder may be longer than the usual period of follow up in the studies (one to two years).

There is marked heterogeneity both in the size of the samples used and in the social cognitive tests applied, bringing difficulties to compare the studies.

The use one single test to measure a specific aspect of social cognition may not be sufficient to measure the degree of impairment in social cognition, since an individual may show good performance in easier tasks (eg., emotion recognition in faces), but exhibit deficits in the ability to discriminate more complex kinds of social information (eg., emotion recognition in dynamic scenes or in prosody).

Impairments in neurocognition are well described in schizophrenia and may impair the accurate evaluation of social cognition, since some of its domains depend upon the good functioning of basic cognitive functions. It is not clear how neurocognition, social cognition and symptom domains interact with each other.

With respect to interventions, the studies do not clearly discuss learning effects of multiple applications of the tests in the same patients. The outcome may be influenced not only by the intervention, but also by the clinical condition of the patient. 


\section{References}

Aakre, J.M.; Seghers J.P.; St-Hilaire A. \& Docherty, N. (2009). Attributional style in delusional patients: a comparison of remitted paranoid, remitted nonparanoid, and current paranoid patients with nonpsychiatric controls. Schizophrenia Bulletin. Vol. 35, (September 2009), pp. 994-1002

Achim A.M.; Ouellet, R.; Roy, M.A. \& Jackson, P.L. (2010). Assessment of empathy in firstepisode psychosis and meta-analytic comparison with previous studies in schizophrenia. Psychiatry Research. ( December 2010). [Epub ahead of print]

Addington, J. (2004). The diagnosis and assessment of individuals prodromal for schizophrenic psychosis. CNS Spectrums. Vol. 9, No 8. (August 2004), pp.588-94

Addington, J.; Penn, D.; Woods, S.W.; Addington, D. \& Perkins, D.O. (2008). Facial affect recognition in individuals at clinical high risk for psychosis. The British journal of psychiatry : the journal of mental science. Vol. 192, No 1, (January 2008), pp. 67-68

Addington, J.; Saeedi, H. \& Addington, D. (2006). Facial affect recognition: a mediator between cognitive and social functioning in psychosis? Schizophrenia Research. Vol. 85, No 1-3, (July 2006), pp. 142-50.

Adolphs R.; Tranel D.; Damasio H. \& Damasio A. (1994). Impaired recognition of emotion in facial expressions following bilateral damage to the human amygdala. Nature, Vol.372, (1994), pp. 669-672.

Adolphs, R. (2001). The neurobiology of social cognition. Current Opinion in Neurobiology, Vol.11, (2001), pp. 231-239

Amminger, G.P.; Schäfer, M.R.; Papageorgiou, K.; Klier, C.M.; Schlögelhofer, M.; Mossaheb, N.; An, S.K.; Kang, J.I.; Park, J.Y.; Kim, K.R.; Lee, S.Y.\& Lee, E. (2010). Attribution bias in ultra-high risk for psychosis and first-episode schizophrenia. Schizophrenia Research. Vol. 118, No 1-3, (May 2010), pp. 54-61.

Barch D.M. (2010). Pharmacological strategies for enhancing cognition in schizophrenia. (2010). Current Top Behavior Neuroscience. (january 2010), pp. 43-96

Bechara, A.; Damasio, H; \& Damasio, A. (2003). Role of the amygdala in decision-making. Annals of the New York Academy of Sciences, Vol.985, (2003), pp. 359-369

Behere, R.V.; Venkatasubramanian, G; Arasappa, R.; Reddy, N. \& Gangadhar, B.N. (2009). Effect of risperidone on emotion recognition deficits in antipsychotic-naïve schizophrenia: a short-term follow-up study. Schizophrenia Research. Vol. 113, No 1, (August 2009), pp. 72-6

Bentall, R.P.; Corcoran, R.; Howard, R.; Blackwood, N. \& Kinderman, P. (2001). Persecutory delusions: a review and theoretical integration. Clinical Psychology Review. Vol. 21, No 8, (November 2001), pp. 1143-92

Bertrand, M.C.; Sutton, H.; Achim, A.M.; Malla, A.K. \& Lepage, M. (2007). Social cognitive impairments in first episode psychosis. Schizophrenia Research. Vol. 95, No 1-3, (September 2007), pp. 24-33

Bonshtein, U. (2006). Theory of mind in schizophrenia. Harefuah. Vol. 145, No 12, (December 2006), pp. 926-931, 939.

Bora, E. (2009). Theory of mind in schizophrenia spectrum disorders. Turkish Journal of Psychiatry. Vol. 20, No 3, (2009), pp. 269-81 
Bora, E.; Yucel, M. \& Pantelis, C. (2009). Theory of mind impairment in schizophrenia: metaanalysis. Schizophrenia Research. Vol. 109, No 1-3, (February 2009), pp. 1-9

Brown, L.A. \& Cohen, A.S. (2010). Facial emotion recognition in schizotypy: the role of accuracy and social cognitive bias. Journal of the International Neuropsychological Society. Vol.16, No 3, (May, 2010), pp. 474-83

Brüne, M. \& Brüne-Cohrs, U. (2006). Theory of mind - evolution, ontogeny, brain mechanisms and psychopathology. Neuroscience and Biobehavioral Reviews. Vol.30, (2006), pp. 437-455.

Brüne, M. (2005). Theory of mind" in schizophrenia: a review of the literature. Schizophrenia Bulletin. Vol. 3, No 1, (January 2005), pp. 21-42

Cabral-Calderin, Y. \& Mendoza-Quiñones R.,; Garcia, A.; Caballero, A.; Dominguez, M.; Reyes, M.M. (2010). Effect of quetiapine treatment on facial emotion recognition deficits in schizophrenia patients. Schizophrenia Research. Vol. 119, No 1-3, (april 2010), pp. 275-6

Choi, K. \& Kwon, J. (2006). Social Cognition Enhancement Training for Schizophrenia: A Preliminary Randomized Controlled Trial. Community Mental Health Journal. Vol. 42, No 2, (April 2006), pp. 177-187

Chung, Y.S.; Kang, D.H.; Shin, N.Y.; Yoo, S.Y. \& Kwon, J.S. (2008). Deficit of theory of mind in individuals at ultra-high-risk for schizophrenia. Schizophr Research. Vol. 99, No 1-3, (February 2008), pp. 111-8

Couture S.M.; Penn D.L. \& Roberts D.L. (2006). The functional significance of social cognition in schizophrenia: a review. Schizophrenia Bulletin, Vol.32, No.S1, (2006), pp. S44-S63.

Couture, S.M.; Penn, D.L.; Addington, J.; Woods, S.W. \& Perkins, D.O. (2008). Assessment of social judgments and complex mental states in the early phases of psychosis. Schizophrenia Research, Vol.100, No.1-3, (March 2008), pp. 237-241

Del Prette, Z.A.P. \& Del Prette, A. (2009). Psicologia das Habilidades Sociais: terapia, educação e trabalho. pp. 37-38. Editora Vozes, ISBN 978-85-326-2142-9, Rio de Janeiro.

Diez-Alegría, C.; Vázquez, C.; Nieto-Moreno, M.; Valiente, C. \& Fuentenebro F. (2006). Personalizing and externalizing biases in deluded and depressed patients: are attributional biases a stable and specific characteristic of delusions? (2006). Journal Clinical Psychological. Vol. 45, No 4, (November 2006), pp. 531-44

Eack, S.M.; Mermon, D.E.; Montrose, D.M.; Miewald, J.; Gur, R.E.; Gur, R.C.; Sweeney, J.A. \& Edwards, J., Pattison, P.E.; Jackson, H.J. \& Wales, R.J. (2001). Facial affect and affective prosody recognition in first-episode schizophrenia. Schizophrenia Research. Vol. 30, No 48, 2-3, (March 2001), pp. 235-53

Emery N. \& Amaral D. (2000). The role of the amygdala in primate social cognition. in R. Lane \& L. Nadel (Orgs.), Cognitive neurosciencie of emotion, pp. 570-600, Oxford: Oxford University Press.

Emery, N.J \& Clayton, N.S. (2009). Comparative social cognition. Annual review of psychology. Vol. 60, No 87, (2009), pp. 87-113 
Erol, A.; Mete, L.; Sonmez, I. \& Unal, E.K. (2010). Facial emotion recognition in patients with schizophrenia and their siblings. Nordic Journal of Psychiatry. Vol. 64, No 1, (2010), pp. 63-7

Fakra, E.; Salgado-Pineda, P.; Besnier, N; Azorin, J.M. \& Blin, O. (2009). Risperidone versus haloperidol for facial affect recognition in schizophrenia: findings from a randomised study. World Journal Biology Psychiatry. Vol. 10, No 4, (January 2009), pp. $719-28$

Fett, A-K.J.; Viechtbauerb, W. \& Domingueza, M.G. (2011). The relationship between neurocognition and social cognition with functional outcomes in schizophrenia: A meta-analysis. Neuroscience and Biobehavioral Reviews. Vol. 35, (2011), pp. 573-588

Frommann, I.; Pukrop, R.; Brinkmeyer, J.; Bechdolf, A.; Ruhrmann, S.; Berning, J.; Decker, P.; Riedel, M.; Möller, H.J.; Wölwer, W.; Gaebel, W.; Klosterkötter, J.; Maier, W. \& Wagner, M. (2011). Neuropsychological Profiles in Different At-Risk States of Psychosis: Executive Control Impairment in the Early and Additional Memory Dysfunction in the Late-Prodromal State. Schizophrenia Bulletin. Vol. 37, No 4, (July 2011), pp. 861-73.

Fuentes, D.; Lunardi, L.L.; Malloy-Diniz, L. F. \& Rocca, C.C. de A. (2010). Cap. 15. Reconhecimento de Emoções, in Avaliação Neuropsicológica. Malloy-Diniz, L.F.; Fuentes, D.; Mattos, P.; Abreu, N. \& Cols. pp. 169-174. Editora Artmed, ISBN 97885-363-2210-0, Porto Alegre.

Galderisi, S.; Piegari, G.; Mucci, A.; Acerra, A.; Luciano, L.; Rabasca, A.F.; Santucci, F.; Valente, A.; Volpe M.; Gibson, C.M.; Penn, D.L.; Prinstein, M.J.; Perkins, D.O. \& Belger, A. (2010). Social skill and social cognition in adolescents at genetic risk for psychosis. Schizophrenia Research. Vol. 122, No 1-3, (September 2010), pp. 179-184

Granholm, E; Ben-zeev, Dror. \& Link, P.C. (2009). Social desinterest attitudes and group cognitive-behavioral social skills training for functional disability in schizophrenia. (2009). Schizophrenia Bulletin. Vol. 35, No 5, (July 2009), pp. 874-883

Green, M.F.; Bearden, C.E.; Cannon, T.D.; Fiske, A.P.; Hellemann, G.S.; Horan, W.P.; Kee, K.; Kern, R.S.; Lee, J.; Sergi, M.J.; Subotnik, K.L.; Sugar, C.A.; Ventura, J.; Yee, C.M. \& Nuechterlein, K.H. (2011). Social Cognition in Schizophrenia, Part 1: Performance Across Phase of Illness. Schizophrenia Bulletin. 2011 (Feb 23). [Epub ahead of print]

Horan, W.P.; Kern, R.S.; Shokat-Fadai, K.; Sergi, M.J.; Wynn, J.K. \& Green, M.F. (2008). Social cognitive skills training in schizophrenia: an initial efficacy study of stabilized outpatients. Schizophrenia Research. Vol. 107, No 1, (January 2009), pp. 47-54

Horton, H.K. \& Silverstein, S.M.(2008). Social cognition as a mediator of cognition and outcome among deaf and hearing people with schizophrenia. Schizophrenia Research. Vol. 105, (August 2008), pp. 125-137

Ibarrarán-Pernas, G.Y.; Guevara, M.A.; Cerdán, L.F. \& Ramos-Loyo, J. (2003). Olanzapine effects on emotional recognition in treatment refractory schizophrenics. Actas Esp Psiquiatry. Vol. 31, No 5, (October 2003), pp. 256-62

Janssen, I.; Versmissen, D.; Campo, J.A.; Myin-Germeys, I.; van Os J \& Krabbendam, L. (2006). Attribution style and psychosis: evidence for an externalizing bias in patients but not in individuals at high risk. Psychological Medicine. Vol. 36, No 6, (June 2006), pp. 771-8 
Kim, H.S.; Shin, N.Y.; Choi, J.S.; Jung, M.H.; Jang, J.H.; Kang, D.H. \& Kwon, J.S. (2010). Processing of facial configuration in individuals at ultra-high risk for schizophrenia. Schizophrenia Research. Vol. 118, No 1-3, (May 2010), pp. 81-7

Keshavan, M.S. (2010). Social cognition deficits among individuals at familial high risk for schizophrenia. Schizophrenia Bulletin. Vol. 36, No 6, (November 2010), pp.1081-8

Koelkebeck, K.; Pedersen, A.; Suslow, T.; Kueppers, K.A.; Arolt, V. \& Ohrmann, P. (2010). Theory of Mind in first-episode schizophrenia patients: correlations with cognition and personality traits. Schizophrenia Research. Vol. 119, No 1-3, (June 2010), pp. 11523

Kohler, C.G.; Turner, T.H.; Gur, R.E. \& Gur, R.C. (2004). Recognition of facial emotions in neuropsychiatric disorders. CNS Spectrums. Vol.9, No. 4, (2004), pp. 267-275

Kohler, C.G.; Martin, E.A.; Kujawski, E.; Bilker, W.; Gur R.E. \& Gur, R.C. (2007). No effect of donepezil on neurocognition and social cognition in young persons with stable schizophrenia. Cognition Neuropsychiatry. Vol. 12, No 5, (September 2007), pp. 41221

Kohler, C.G.; Walker, J. B.; Martin, E.A.; Healey, K.M.; \& Moberg, P.J. (2010). Facial emotion perception in schizophrenia: a meta-analytic review. Schizophrenia Bulletin. Vol. 36, No 5, (September 2010), pp. 1009-19

Kraemer, H.C. \& Kupfer, D.J.(2005). Size of treatment effects and their importance to clinical research and practice. Biological Psychiatry. Vol. 59, No 11, (June 2006), pp. 990-6

Krstev, H.; Jackson, H. \& Maude, D. (1999). An investigation of attributional style in firstepisode psychosis. British Journal of Social and Clinical Psychology. Pt 2, (June 1999), pp. 181-94

Krueger F.; Barbey A.K. \& Grafman J. (2009). The medial prefrontal cortex mediates social event knowledge. Trends Cognition Science. Vol.13, (Febrary 2009), [Epub ahead of print]

Kurtz, M.M. \& Richardson, C.L. (2011). Social Cognitive Training for Schizophrenia: A Meta-Analytic Investigation of Controlled Research. Schizophrenia Bulletin. Vol.27, (April 2011), pp. 1-13.

Kurzban, S.; Davis, L. \& Breke, J.S. (2010). Vocational, Social, and Cognitive Rehabilitation for individuals diagnosed with schizophrenia: a review of recent research and trends. Current Psychiatry Rep. Vol. 12, (June 2010), pp. 345-355

Lewis, S.F. \& Garver, D.L. (1995). Treatment and diagnostic subtype in facial affect recognition in schizophrenia. Journal Psychiatry Research. Vol. 29, No 1, (JanuaryFebruary 1995), pp. 5-11

Li, H.; Chan, R.C.; Zhao, Q.; Hong, X. \& Gong, Q.Y. (2010). Facial emotion perception in Chinese patients with schizophrenia and non-psychotic first-degree relatives. Progress in Neuro-Psychopharmacology and Biological Psychiatry. Vol. 34, No 2, (March 2010), pp. 393-400.

Littrell, K.H.; Petty, R.G.; Hilligoss, N.M.; Kirshner, C.D. \& Johnson, C.G. (2004). Improvement in social cognition in patients with schizophrenia associated with treatment with olanzapine. Schizophrenia Research. Vol. 66, No 2-3, (February 2004), pp. 201-2 
Mastantuono, P. \& Maj, M.(2010). Social skills and neurocognitive individualized training in schizophrenia: comparison with structured leisure activities. Europe Archiment Psychiatry Clinical Neuroscience. Vol. 260, No 4, (October 2009), pp. 305-15

Marwick, K. \& Hall, J. (2008). Social cognition in schizophrenia: a review of face processing. British Medical Bulletin. Vol. 88, No 1, (2008), pp. 43-58

Medalia, A. \& Choi, J. (2009). Cogntive remediation in schizophrenia. (2009). Neuropsychological Reviews. Vol. 19, No 3, (May 2009), pp. 353-364

McGorry, P.D.; Yung, A.R. \& Phillips, L.J. (2003). The "close-in" or ultra high-risk model: a safe and effective strategy for research and clinical intervention in prepsychotic mental disorder. Schizophrenia Bulletin. Vol. 29, No 4, (2003), pp. 771-90

Mishara, A.L. \& Goldberg, T.E. (2004). A meta-analysis and critical review of the effects of conventional neuroleptic treatment on cognition in schizophrenia: opening a closed book. Biology Psychiatry. Vol. 55, No 10, (May 2004), pp. 1013-22

Mizrahi R.; Addington, J.; Remington, G. \& Kapur, S. Attribution style as a factor in psychosis and symptom resolution. (2008). Schizophrenia Research. Vol.104, No 1-3, (July 2008), pp. 220-7

Mizrahi R.; Korostil, M.; Starkstein, S.E.; Zipursky, R.B. \& Kapur, S. The effect of antipsychotic treatment on Theory of Mind. (2007). Psychological Medicine. Vol. 37, No 4, (November 2006), pp. 595-601

Mizrahi, R.; Addington, J.; Remington, G. \& Kapur, S. (2008). Attribution style as a factor in psychosis and symptom resolution. Schizophrenia Bulletin. Vol. 104, No 1-3, (September 2008), pp. 220-7

Monteiro, L.C. \& Louzã, M.R. (2010). Cap. 14. Cognição Social, in Avaliação Neuropsicológica. Malloy-Diniz, L.F.; Fuentes, D.; Mattos, P.; Abreu, N. \& Cols. pp. 162-168. Editora Artmed, ISBN 978-85-363-2210-0, Porto Alegre.

Monteiro, L.C.; Queiroz, F.P. \& Rössler, W. (2010). Cap. 16. Teoria da Mente, in Avaliação Neuropsicológica. Malloy-Diniz, L.F.; Fuentes, D.; Mattos, P.; Abreu, N. \& Cols. pp. 175-182. Editora Artmed, ISBN 978-85-363-2210-0, Porto Alegre

Morris, R.W.; Weickert, C.S. \& Loughland, C.M. (2009). Emotional face processing in schizophrenia. Current Opinion in Psychiatry. Vol. 22, No 2, (March 2009), pp. 140-6

Niendam, T.A.; Bearden, C.E.; Zinberg, J.; Johnson, J.K.; O'Brien, M. \& Cannon, T.D. (2007). The course of neurocognition and social functioning in individuals at ultra high risk for psychosis. Schizophrenia Bulletin. Vol. 33, No 3, (May, 2007), pp. 772-81

Ochsner, K.N. Current directions in social cognitive neuroscience. Current Opinion in Neurobiology, Vol.14, No. 2, (2004), pp. 254-258

Park, K.; Ku, J.; Choi, S.; Jang, H.; Park, J.; Kim, S.I. \& Kim, J. (2011). A virtual reality application in role-plays of social skills training for schizophrenia: a randomized, controlled trial. Psychiatry Research. (April 2011), pp. 1-7

Patel, A.; Knapp, M.; Romeo, R.; Reeder, C.; Matthiasson, P.; Everitt, B. \& Wykes, T. (2010). Cognitive remediation therapy in schizophrenia: cost-effectiveness analysis. Schizophrenia Research. Vol. 120, No 3, (January 2010), pp. 217-24

Pedersen, C.A.; Gibson, C.M.; Rau, S.W.; Salimi, K.; Smedley, K.L.; Casey, R.L.; Leserman, J.; Jarskog, L.F. \& Penn, D.L. (2011). Intranasal oxytocin reduces psychotic symptoms 
and improves Theory of Mind and social perception in schizophrenia. Schizophrenia Research. (August 2011), [ahead of print]

Penn, D.L.; Sanna, L.J. \& Roberts, D.L. (2008). Social cognition in schizophrenia: an overview. Schizophrenia Bulletin, Vol.34, No. 3, pp. 408-411

Penn, D.L.; Keefe, R.S.; Davis, S.M.; Meyer, P.S.; Perkins, D.O.; Losardo, D. \& Lieberman, J.A. (2009). The effects of antipsychotic medications on emotion perception in patients with chronic schizophrenia in the CATIE trial. Schizophrenia Research. Vol. 115, No 1, (September 2009), pp. 17-23

Penn, D.L.; Roberts, D.L.; Combs, D. \& Sterne, A. (2007). The development of the social cognition and interction training program for schizophrenia spectrum disorders. Psichiatric services. Vol. 58, No 4, (April 2007), pp. 449-451

Penn, D.L.; Sanna, L.J. \& Roberts, D.L. (2008). Social cognition in schizophrenia: an overview. Schizophrenia bulletin. Vol. 34, No 3, (March 2008), pp. 408-11

Penn, D.L.; Corrigan, P.W.; Bentall, R.P. \& Racenstein, J.M. (1997). Social cognition in schizophrenia. Psychological Bulletin, Vol.121, No. 1, (1997), pp. 114-132.

Peters E. \& Garety P. Cognitive functioning in delusions: a longitudinal analysis. Behavior Research Therapy. Vol. 44, No 4, (April 2006), pp. 481-514

Pinkham, A.E.; Penn, D.L.; Perkins, D.O.; Graham, K.A. \& Siegel, M. (2007). Emotion perception and social skill over the course of psychosis: a comparison of individuals "at-risk" for psychosis and individuals with early and chronic schizophrenia spectrum illness. Cognitive Neuropsychiatry. Vol. 12, No3, (May. 2007), pp. $198-212$

Reed, S. I. (2008). First-episode psychosis: A literature review. International Journal of Mental Health Nursing. Vol. 17, (2008), pp. 85-91

Rocca, C.C.A.; Polisel, A.F.; Mattos, K.M.G. \& Silva, M.C.F. (2010). Cap. 17. Habilidades Sociais, in Avaliação Neuropsicológica. Malloy-Diniz, L.F.; Fuentes, D.; Mattos, P.; Abreu, N. \& Cols. pp. 183-197. Editora Artmed, ISBN 978-85-363-2210-0, Porto Alegre

Sachs, G.; Steger-Wuchse, D.; Kryspin-Exner, I.; Gur, R.C. \& Katschnig, H. (2004). Facial recognition deficits and cognition in schizophrenia. Schizophrenia Research. Vol. 1, No 68-1, (May, 2004), pp.27-35

Satpute A.B. \& Lieberman M.D. (2006). Integrating automatic and controlled processes into neurocognitive models of social cognition. Brain Research. Vol.1079, (2006), pp. 8697

Savina I. \& Beninger, R.J. Schizophrenic patients treated with clozapine or olanzapine perform better on theory of mind tasks than those treated with risperidone or typical antipsychotic medications. (2007). Schizophrenia Research. Vol. 94, No 1-3, (June 2007), pp. 128-38

Scoriels, L.; Barnett, J.H.; Murray, G.K.; Cherukuru, S.; Fielding, M.; Cheng, F.; Lennox, BR.; Sahakian, B.J. \& Jones, P.B. (2010). Effects of modafinil on emotional processing in first episode psychosis. Biological Psychiatry. Vol. 69, No 5, (December 2011), pp. 457-64 
Seligman, M. E. P.; Nolen-Hoeksema, S.; Thornton, N. \& Thornton, K. M. (1990). Explanatory style as a mechanism of disappointing athletic performance. Psychological Science. Vol.1, (1990), pp.143-146

Sergi, M.J.; Green, M.F.; Widmark, C.; Reist, C.; Erhart, S.; Braff, D.L.; Kee, K.S.; Marder, S.R. \& Mintz, J. (2007). Social cognition and neurocognition: effects of risperidone, olanzapine, and haloperidol. American Journal Psychiatry. Vol. 164, No 10, (October 2007), pp. 1585-92

So, S.H.; Garety, P.A.; Peters, E.R. \& Kapur, S. (2010). Do antipsychotics improve reasoning biases? A review. Psychossomatic Medicine. Vol. 72, No 7, (July 2010), pp. 681-93

Sparks A.; McDonald, S.; Lino, B.; O'Donnell, M. \& Green, M.J. (2010). Social Cognition, empathy and functional outcome in schizophrenia. Schizophrenia Research. Vol. 122, (May 2010), pp. 172-8

Sprong, M.; Schothorst, P.; Vos E.; Hox, J. \& van Engeland, H. (2007). Theory of mind in schizophrenia: meta-analysis. The British journal of psychiatry : the journal of mental science. Vol. 191 (Jul. 2007), pp. 5-13.

Swerdlow, N.R. (2011). Are we studying and treating schizophrenia correctly? Schizophrenia Research. Vol. 130, No 1-3, (June 2011), pp. 1-10

The British journal of psychiatry: the journal of mental science. Vol. 109, No 1-3, (April 2009), pp. 1-9

Thompson, A.D.; Bartholomeusz, C. \& Yung, A.R. (2011). Social cognition deficits and the 'ultra high risk' for psychosis population: a review of literature. Early Intervention in Psychiatry. Vol. 5, No 3, (Aug. 2011), pp. 192-202

Thornton, A.E.; Van Snellenberg, J.X.; Sepehry, A.A. \& Honer, W. (2005). The impact of atypical antipsychotic medications on long-term memory dysfunction in schizophrenia spectrum disorder: a quantitative review. Journal Psychopharmacological. Vol. 20, No 3, (September 2005), pp. 335-46

Tonelli, H. A.; Alvarez, C. E. \& Silva, A. A. (2009). Esquizotipia, "Teoria da Mente" habilidades e vulnerabilidade à psicose: uma revisão sistemática. Revista Psiquiatria Clínica. Vol. 36, No 6, (2009), pp.229-239. ISSN 0101-6083

Veltro, F.; Mazza, M.; Venditelli, N.; Alberti, M.; Casacchia, M. \& Roncone, R. (2011). A comparison of the effectiveness of problem solving training and of cognitiveemotional rehabilitation on neurocognition, social cognition and social functioning in people with schizophrenia. Clinical Practice e Epidemiology in Mental Health, No 7, (July 2011), pp. 123-132

Woodward, N.D.; Purdon, S.E.; Meltzer, H.Y. \& Zald, D.H. (2005). A meta-analysis of neuropsychological change to clozapine, olanzapine, quetiapine, and risperidone in schizophrenia. International Jounal Neuropsychopharmacological. Vol. 8, No 3, (March 2005), pp. 457-72

Werneck-Rohrer. S.; Nelson, B. \& McGorry, P.D. (2011). Emotion Recognition in Individuals at Clinical High-Risk for Schizophrenia. Schizophrenia Bulletin. (March 2011), pp. 21

Wykes, T.; Huddy, V.; Cellard, C.C.; McGurk, S.R. \& Czoborp. (2011). A meta-analysis of cognitive remediation for schizophrenia: methodoly and effect sizes. American Journal Psychiatry. Vol. 168, (May 2011), pp. 472-485 
Wykes, T.; Newton, E; Landau, S.; Rice, C.; Thompson, N. \& Frangou, S.(2008). Cognitive remediation therapy (CRT) for young early onset patients with schizophrenia: An exploratory randomized controlled trial. Schizophrenia Research. Vol. 94, No 1-3, (November 2008), pp. 221-3 


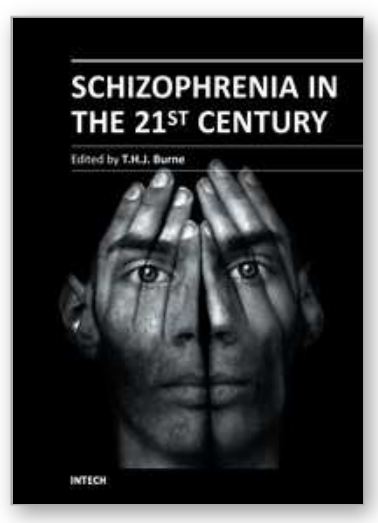

\author{
Schizophrenia in the 21st Century \\ Edited by Dr. T.H.J. Burne
}

ISBN 978-953-51-0315-8

Hard cover, 180 pages

Publisher InTech

Published online 23, March, 2012

Published in print edition March, 2012

Schizophrenia is a poorly understood but very disabling group of brain disorders. While hallucinations and delusions (positive symptoms of schizophrenia) feature prominently in diagnostic criteria, impairments of memory and attentional processing (cognitive symptoms of schizophrenia) are attracting increasing interest in modern neuropsychiatry. Schizophrenia in the 21 st Century brings together recent findings on this group of devastating disorders. We are still a long way from having effective treatment options, particularly for cognitive symptoms, and lack effective interventions and ways to prevent this disease. This volume covers various current options for therapy, clinical research into cognitive symptoms of schizophrenia and preclinical research in animal models.

\title{
How to reference
}

In order to correctly reference this scholarly work, feel free to copy and paste the following:

Luciana de Carvalho Monteiro, Paula Andreia Martins, Marisa Crivelaro and Mario Rodrigues Louzã (2012). Schizophrenia and Social Cognition: From Conceptual Bases to Therapeutic Approaches, Schizophrenia in the 21st Century, Dr. T.H.J. Burne (Ed.), ISBN: 978-953-51-0315-8, InTech, Available from: http://www.intechopen.com/books/schizophrenia-in-the-21st-century/schizophrenia-and-social-cognition-fromconceptual-bases-to-therapeutic-approaches

\section{INTECH}

open science | open minds

\author{
InTech Europe \\ University Campus STeP Ri \\ Slavka Krautzeka 83/A \\ 51000 Rijeka, Croatia \\ Phone: +385 (51) 770447 \\ Fax: +385 (51) 686166 \\ www.intechopen.com
}

\author{
InTech China \\ Unit 405, Office Block, Hotel Equatorial Shanghai \\ No.65, Yan An Road (West), Shanghai, 200040, China \\ 中国上海市延安西路65号上海国际贵都大饭店办公楼 405 单元 \\ Phone: +86-21-62489820 \\ Fax: +86-21-62489821
}


(C) 2012 The Author(s). Licensee IntechOpen. This is an open access article distributed under the terms of the Creative Commons Attribution 3.0 License, which permits unrestricted use, distribution, and reproduction in any medium, provided the original work is properly cited. 